\title{
Veins and fracture coatings linked to tectonic events by in situ Rb-Sr LA- ICP-MS/MS dating
}

MIKAEL TILLBERG ${ }^{1,2}$, HENRIK DRAKE ${ }^{1}$, MR. THOMAS

$$
\text { ZACK }^{3} \text { AND JOHAN HOGMALM }{ }^{2}
$$

${ }^{1}$ Linnaeus University

${ }^{2}$ University of Gothenburg

${ }^{3}$ Department of Earth Sciences, University of Gothenburg

Presenting Author: mikael.tillberg@lnu.se

Minerals formed in fractures and veins by intermittent fracture reactivation and fluid migration constitute archives of the tectonic evolution of Precambrian cratons. These mineralogical records feature complex intergrowth patterns of fine-grained vein generations and discrete mineral zonations that are difficult to target by bulk dating methods. Instead, absolute ages of mineralization events can be constrained by applying in situ Rb$\mathrm{Sr}$ dating via triple quadrupole laser ablation inductively coupled plasma mass spectrometry (LA-ICP-MS/MS) on veins and single fracture crystal growth zones $[1,2]$.

We utilize in situ $\mathrm{Rb}$-Sr dating of a wide range of coeval $\mathrm{K}$ and Ca-rich mineral assemblages to distinguish discrete vein generations at three Paleoproterozoic crystalline bedrock sites in Sweden, separated by over $300 \mathrm{~km}$. The resulting age clusters link veining and fracturing to tectonic events affecting the Fennoscandian Shield up to a billions years apart. Coupled textural and structural analysis and in situ dating of grain growth zones anchors veins and fracture-hosted mineral precipitation to fluid migration fracture reactivation episodes across the Fennoscandian Shield, enabling reconstruction of far-field orogenic activity and foreland basin evolution.

This new approach for resolving geological histories of Precambrian cratons connects micro-scale age determinations of individual grains and veins with regional-scale crustal dynamic responses to tectonic events. Furthermore, the study demonstrates the advancing applicability of the in situ Rb-Sr LAICP-MS/MS dating method for tracing hydrothermal systems.

[1] Tillberg et al. (2019), Geofluids. [2] Tillberg et al. (2020), Scientific. Reports. 10, 1-13. 